\title{
THE CHALLENGES OF FORMALIZATION AND MODELING OF HIGHER EDUCATION INSTITUTIONS IN THE 21ST CENTURY

\author{
Ivars Linde $^{1}$, Mariana Petrova ${ }^{2}$
}

\begin{abstract}
This study is aimed at the analysis and development of methodologies to ensure and manage the quality of higher education. There have been radical changes and transformation of the postindustrial society into a global information society on the basis of knowledge and competence, and the increased external demands from society to the result of higher education have significantly influenced the development of higher education at the end of the 20th century. Accordingly, the roles, organizational forms and ways of functioning of higher education institutions (HEIs) have changed as one of the basic elements of the higher education system, ensuring the development of economic, social, cultural and global, national and regional communities as a whole. The current system of education is characterized by the virtual absence of institutions responsible for the results of their activities. Not sufficiently independent forms and mechanisms of participation of citizens, employers, professional associations on the development of educational policy have not been developed. There are no structures for an independent assessment of the quality of education.

As a result of adaptation to the global information society, the classical model of the HEI was transformed, which manifested itself in the formation of a new type of HEI. The vector of transformation of the models of HEI were not only accompanied by diverse organizational change and revisions of the missions of universities, but also by the formation of strategic management as a factor in-system with the release of its organizational and functional entity. In the article, as a form of presentation of scientific methodologies of social processes and objects, a triad hierarchical model is proposed, represented in the form of a hierarchical system containing levels: system, structure, inter-system exchange, movement and applied fields of knowledge. Thus, the essence of the approach is to develop a triadic concept and its application to describe the structures of social objects and processes and construct different classes of models to study their properties and improve management processes, taking into account the human factor.

In the future, the proposed methodology can provide the most appropriate solution to ensure a comprehensive and highquality higher education.
\end{abstract}

JEL Classification Numbers: I20, M10; DOI: http://dx.doi.org/10.12955/cbup.v6.1173

Keywords: higher education, quality, strategic management

\section{Introduction}

The evolutionary approach allows us to propose appropriate methodologies for strategic management. It should also be noted that the evolutionary analysis of existing approaches shows the inadequate use of all the possibilities of basic social and economic research and management theories of social and economic systems. In this situation and despite its relevance, the problem of research and modeling of the management system on the basis of the evolutionary approach is still insufficiently understood.

The analysis of management practice of universities has revealed a number of functional features and differences in the systems of strategic management for different models of the university, which is complicated by the specific and special role in the society.

\section{Methodology for the strategic management}

An evolutionary approach allows us to offer an adequate methodology. At the same time, the evolutionary analysis of existing approaches shows that they remain away from the main socioeconomic research and management theory of social and economic systems. The problem of the studying and the modeling of control system based on an evolutionary approach, in spite of its relevance, is insufficiently studied.

The Higher education institution, a social-economic object, is considered a complicated and dynamically developing system of social activities. However, productive management of the quality of education is not possible without the transition of subjective description of pedagogical processes to its objective evaluations. The above mentioned issue of the quality of higher education and the necessity of use of new technologies has been investigated by the following authors - "teaching itself is a never ending process" (Argyris and Schön, 1974), "quality is unarguably a multi-layered concept"(Linde, 2012), (Biggs, 2001), "quality stems from its stakeholder-relative characteristics" (Tam, 2001), "the organized education in Bulgaria more or less moves along the strenuous course of development and application of its own or established in practice new technologies of learning" (Nenkov et al., 2017).

\footnotetext{
${ }^{1}$ ISMA University, Riga, Latvia, PhD student, ivars.linde@isma.lv

2 St.Cyril and St.Methodius University of Veliko Tarnovo, Bulgaria m.petrova@ts.uni-vt.bg
} 
The main factors affecting the university governance system modeling are: globalization, increasing the pace of technological change, rapid and unexpected changes in the field of information and communication technologies, the formation of new, market-based relations in the education system, increasing competition for resources between HEI, causing the emergence of new providers of educational services, the diversification of sources of financing, demographic changes due to the decline in the birth rate and emigration of potential students, and the new needs of society in the field of education and more demanding consumers. In the post-Soviet space, such as in Latvia and Bulgaria, the situation of introduction new socio-economic systems is complemented by the inevitable change in the legal framework for higher education institutions after the separation from the USSR and the restructuring of educational programs according to the requirements of the Bologna Process.

Trends in the external environment of the HEI and the associated threats and opportunities significantly affect the role, organizational forms and ways of functioning of HEI around the world.

As a result of adaptation to new conditions and requirements, the traditional model of the HEI was forced to change, and a new type of HEI was formed, where entrepreneurship, innovation, research, orientation to the project approach, access to the regions, and the virtuality of education was accentuated.

Currently, a host of papers have appeared on the strategic management of HEI, which have successfully worked out the problems relating to the various approaches, from the development of the strategy to its implementation.

Analysis of management practices of universities showed a number of functional features and content of strategic management system, which is typical for different models of the universities. Application of strategic management to HEIs is complicated by a number of problems that can be divided into two groups: technological and methodological.

The problems of the technological nature include a lack of reliability in the results of forecasting the development of a HEI and the state of its environment, a lack of adequate experience in the development and implementation of effective strategies, the non-system use of technologies of strategic management, a lack of qualified senior management structure for the use of modern management techniques, etc.

Methodological issues include the overall failure of the school in strategic planning. Direct transfer of strategic planning at a HEI is also complicated by the specific and special role of HEIs in society.

The authors distinguish five levels of knowledge, forming a research methodology of strategic management for a HEI.

The first level is system-wide, which gives an explanation of concepts, principles, and the methods of operation of various systems (including organizational).

The second level consists of the knowledge that clarifies the patterns of functioning and development of socio-economic systems.

The third level consists of the knowledge of the laws, principles, and methods of management in the socio-economic systems.

The fourth level forms the knowledge, combining the results from the studies of problems of higher education.

The fifth level is just theory and techniques of strategic management of the HEIs, which presupposes the identification of principles of management, the formation of objectives, functions and structure of management, the organization of interaction between elements of control systems, identifying and forecasting trends in the development of the HEIs, process modeling and management techniques, etc.

The methodological framework of strategic management is a systematic approach. The principles of socio-economic systems are based on the ideas of the classics of cybernetics including J. von Neumann, N. Wiener, W. Ashby and other researchers.

In the framework of a synergetic approach the evolution is presented like a universal form of the system motion, which creates prerequisites for the emergence of alternative approaches to socioeconomic research. Modern concepts of evolutionary economics, evolutionary theories of organizations, resource dependence theory and the theory of strategic management are described in the 
works of C. Andrews, I. Ansoff, Michael Porter, P. Drucker, G. Hamel, C. Prahalad and the other scientists. Among the works of Latvian authors we can mentioned J.Caune, A.Dzedons и I. Kalve.

Let us formulate the basic principles of management. First, the control system continuously analyzes the information about the state of the managed object (the principle of feedback), the control system must have the necessary diversity that takes into account all the different possible states of the control object (the principle of requisite variety). In terms of versatility, it satisfies both the external goals of the system, defining its relationship with the external environment and the internal objectives of the system, aimed at preserving its own structure and to ensure stability, which leads to the principle of duality. Uncertainty and instability of the environment require the implementation of sufficient capacity to change the structure and parameters of the control unit (the principle of adaptability). Finally, the requirement of ensuring the sustainability of the system itself provides the implementation of the principle of static.

The HEI as a socio-economic system is an open and non-linear system, which gives the reason to use a synergistic approach. A synergistic approach allows a new approach to the problem of effective management of the development of socio-economic systems. The new approach to management is that it focuses less on external action, but rather on their own laws of evolution and self-organization.

Reviews of strategic management, that have been widely used in HEI management (in particular, TQM, and BSC), outlined the problems of their application related to the complexity of management of the intellectual assets. Management of the intellectual asset technologies in the educational process combines multiple information technologies, which are based on electronic educational resources.

The importance of the use of cognitive and electronic technologies is noted in the articles of the Bulgarian authors, whose research is aimed at providing quality education and developing opportunities for lifelong learning - «Education in the field of International Economic Relations in the modern age strikes some challenges such as high competitiveness, growing risks, lack of predictability. Management of education as a service is a process aiming to improve the structure of providers of educational services and educational structure of society. » (Nenkov et al., 2017).

Thus, the methodology for the strategic management of HEI-based evolutionary approach is that strategic management should be focused not so much on external influences, but on its own laws of evolution and self-organization. To do this, the system generates the highest hierarchical level of control that closes the feedback loop with the environment and which provides control on the basis of self-organization.

One of the priorities of state policy in education at the present is the improvement of the modern education system and improving the quality of students. Today, the status of all high-tech industries in Latvia is characterized by a significant increase in requirements for training. The solution to this problem requires a change in organizational, methodological and content structure of training and retraining.

In these circumstances is particularly important to find new approaches to a significant increase in the efficiency of management of educational systems and, especially, higher education with a focus on its qualitative aspects. At the same time the control of education means the management of the quality of training at all stages of a continuous process (pre-HEI training, undergraduate and postgraduate training support), which requires the creation of methods and models for further education at any HEI.

Note that the control should be a complex social system, including educational systems, the technical and production systems, where the expert should work.

Currently, Latvia's higher education system produces professionals with a predominance of basic theoretical training in their chosen direction while the market trends lead to the need to acquire a deep knowledge and practical application skills. Overcoming these contradictions requires new teaching methods that provide a science-based combination of the number of educational subjects and courses of both fundamental and applied training in each case.

The systems approach (SA) is a comprehensive methodology for solving scientific and practical problems. While the theory is aimed at obtaining data about the objective reality, the methodology is aimed at the process of obtaining data.

Analysis of the state education system reveals that, despite the great number of concepts, methodologies, techniques and other means of improving the educational process, a product of 
education does not always correspond to modern requirements. We need new methods to improve the quality of students and young professionals. Almost imperceptibly - and without significant state aid or strategy, higher education exports have become an important sector of the economy (Auers and Gubins, 2016).

The changing conditions of production put forward new demands for graduates of the higher educational institutions:

- the ability to independently solve different problems, not only those which are organizational and economic;

- the ability to adequately present the results of his or her labor; having the skills of business communication and personnel management.

In this regard, high efficiency becomes a student-oriented model of training. It is realized most fully in the continuing process of higher education, designed on the basis of a competence-based approach.

A continuing education system is a complex social system, whose states are interpreted as the results of the study, obtained in the course of a superposition of pedagogical decisions (internal exposure) and the signals coming from outside the system (external exposure to the changing labor market). External factors that are not controlled by the educational system create a fatal situation of information, the uncertainty of information in respect of which management decisions are taken. The additional uncertainty generates limited cognitive capabilities of decision makers. This, above all, limits the ability to predict future states of knowledge-intensive industries and the recognition of their current state, as well as the requirements for specialists, which they put forward in 5-10 years. But to achieve such goals, it is necessary to increase funding. For example in general, for the EU ( 28 countries) R\&D expenditure share in GDP increased by 16,67 \% from 2005 (Labunska et al., 2017).

Therefore, an adequate model of the educational system must have the characteristics of the simulation model, that is, take into account the need to make decisions in the context of uncertainty of existing information. Because the state of the educational system and its external influences do not have a statistical nature in the classic sense of mathematical statistics, then modeling based on classical theories of probability and stochastic processes is very difficult.

A review of the practice of education models and decision-making methods show that in most cases they do not correspond to the nature of the specific educational systems and the information situation in which these education models exist. Using the methods of probability theory and mathematical statistics, which are valid only for a place in the same conditions of mass phenomena, they are inadmissible because production conditions and the requirements change every year due to the graduates produced by the educational system.

Fuzzy multiple descriptions are on the one hand, a set of adequate formalisms for modeling of educational systems in considerable uncertainty, while on the other hand, a field for a new interpretation of the classical probability and expert judgment. So, you can go from classical probability distribution to probability distribution with fuzzy parameters, while controlling the level of likelihood estimates of the distribution. The task of modeling the formation of peer review is to adequately determine the qualitative assessment.

From this point of view, the theory of fuzzy sets has a highly formal apparatus. Fuzzy-set descriptions attain maximum efficiency, when the classical or probabilistic optimization methods do not achieve their desired effects or may not contain sufficient justification for their use in models of complex systems.

The analysis showed that, despite the many existing concepts, methodologies, techniques and other means of improving the educational process in the educational system, guidelines are not clearly developed for the selection of students at the stage of "admission" to the university, teaching them as creative persons and monitoring specialists after graduation. These objectives are not clearly defined. Because of their qualitative factors these tasks cannot be completely formalized.

A system analysis of human activities in the areas of public life such as education and science in today's fast pace of development of civilization is of special interest to ensure the quality of these activities, and sustainable human development. 
Despite the huge number of publications, some relevant aspects of this global problem remain poorly understood. Therefore, the author proposes a new description of the systemic form of social processes and objects in the field of scientific and educational systems as a set of triads formed by nine sets of system factors:

$$
S=\left\langle\Phi, H, S t r, Q, P, Z_{\phi}, B, R, Z_{R}\right\rangle,
$$

where $\Phi$ - variety of objects, $H$ - variety of connections, Str - variety of structures, $Q$ - variety of properties, $P$ - variety of parameters, $Z_{\Phi}, Z_{R}$ - variety of goals of functioning and development, $B$ variety of the states of the external environment, $R$ - variety of available resources.

In this first triad $\langle\Phi, H, S t r\rangle$ reflects the structure of the system, the second triad $\left\langle Q, P, Z_{\phi}\right\rangle$ the peculiarities of functioning, the third $\operatorname{triad}\left\langle B, R, Z_{R}\right\rangle$ - the peculiarities of the development of the system. In general, the interaction of sets of these triads can be represented as a hierarchical structure, levels of which reflect the object of study (social systems and processes), the objectives of the movement $\left(Z_{\Phi}, Z_{R}\right)$, the factors affecting the movement of $(B, R, Q)$, and the characteristics of the system $(\Phi, H, S t r, P)$.

A systematic law of triads is formed: one cannot know the full system by examining only a few of the triad, hence there is the need to study the entire set of triads in their relationship and interaction.

Six principles for the formation of triads and triad systems are proposed: the principle of transition, the semantic principle, the principle of goal-based process-forming systems, the hierarchical principle of the formation of triads, the principle of uncertainty-complementarity-compatibility, the principle of multiplication.

As one of the forms representing of the scientific methodologies of the social processes and facilities, a triadic hierarchical model is offered, presented in the form of a hierarchical system containing levels: system, structure, intersystem exchange, movement and the applied areas of knowledge.

The methodology for achieving the goal is presented in the form of the construction of the serial connection of triads, which covers all essential factors affecting the quality of work of the university. It is also proposed to unite the stages of organizational activity into a single system, which reduces the uncertainty of the task of choosing various options in the construction of intermediate stages.

Based on this model, you can build a partial model of competencies, which are integral estimates based on a hierarchical scheme and on the opinions of experts and the present objective information.

Thus, the essence of the approach lies in the development of a triadic concept and applying it as to describe the structures of social objects and processes and building various classes of models for the study of their properties and the improvement of management processes, while taking into account the human factor.

\section{Conclusions}

1. The current education system is characterized by the virtual absence of institutions responsible for the results of their activities. Independent forms and mechanisms of participation of citizens, employers, professional associations in the development of education policy have not been sufficiently developed. There are no structures for an independent assessment of the quality of education.

2. The main strategic task in the field of education is to improve the management of higher education through the realization of an evidence-based approach in the following areas: the realization of integrated models of HEI, the innovation of mechanisms of interaction among higher education institutions and employers in the selection of basic institutions of higher education to improve the efficiency of use of intellectual potential in high school. It is important to concentrate resources on key areas of education development in the interests of the state, society and identity. It is necessary to introduce models of public governance as an important condition for transparency and investment attractiveness of education, improving the effectiveness of institutional management in changing organizational and legal forms of education, creating clusters of HEI and improving the system of education management. 
3. Education is seen as an essential element of national security.

4. The new approach requires a significant correction in the management of education as the most important form of socioeconomic systems, liable for the reproduction of the nation's intellectual potential, especially in terms of improving the quality of educational activities based on an integrated monitoring system that includes assessing the quality of the education system, the ability to predict the development of the education system and a set of corresponding control actions.

5. Education management by the criterion of "quality" should take into account the following factors: the educational system is a complex hierarchical system in which it is impossible to allocate a single object of the management; the education system is reflective system that involves the use of reflective control with the ability to model processes and to develop self-monitoring actions. The integrated monitoring system is the most important problem in the evaluation and control of learning, taking into account the dynamic processes of cognitive activity.

6. Complex research of the models and methods of management of educational processes and systems, including on the basis of an evolutionary approach based on a fuzzy-set approach and the use of cognitive and dynamic modeling and information technologies, shows that to date there has not yet been established a scientific and methodological apparatus possessing a sufficient degree of flexibility to address together the problems of improving management practices in higher education. The main problem is that all attempts to create a universal model of the HEI is probably doomed to failure because the education system belongs to a class of complex systems, for which the use of mathematical modeling in the analytical form is difficult due to the extremely large number of parameters analyzed, and the aggregation of the parameters leads to an unacceptable reduction in the accuracy of the simulation results.

\section{Acknowledgements}

The research is financed by Project № FSD - 31-813/ 28.06.2016 „Developing a web portal of the electronic periodicals of St. Cyril and St. Methodius University of Veliko Tarnovo, Veliko Tarnovo, Bulgaria.

\section{References}

Argyris, C. \& Schön, D. (1974). Theory in practice: Increasing professional effectiveness. San Francisco. Jossey Bass, San Francisco, CA

Auers D. \& Gubins S. (2016). Augstākās izglītības eksporta ekonomiskā nozīme un ietekme Latvijā. Retrieved Jan, 11, 2018 from http://certusdomnica.lv/agenda/augstakas-izglitibas-eksporta-ekonomiska-nozime-un-ietekme-latvija/

Biggs J. (2001). The reflective institution: Assuring and enhancing the quality of teaching and learning. Higher Education, Vol 41 (3), 221-238. DOI: https://doi.org/10.1023/A:1004181331049

Labunska Sv., Petrova M., Prokopishyna O. (2017). Asset and cost management for innovation activity. Economic Annals XXI. VOLUME 165, ISSUE 5-6, Pages: 13-18. DOI: https://doi.org/10.21003/ea.V165-03

Linde I. (2012) Optimization strategies and management problems of higher education. INTED 2012. Proceedings of the 6th International Technology, Education and Development Conference. Valencia, Spain. March, 2012. ISBN: 978-84-615-55635 / ISSN: 2340-1079. Publisher: IATED, pp. 4798-4805

Nenkov, N; Tasinov, T; Petrova, M. (2017). Software system for document management at the Faculty to University, 4th International Multidisciplinary Scientific Conference on Social Sciences and Arts, SGEM 2017. Conference Proceedings, VOL V Science and Society. Book 3, Education \& Educational Research, Pages: 457-464, DOI:10.5593/SGEMSOCIAL 2017/35/S13.060, ISBN 978-619-7408-22-5, ISSN 2367-5659

Nenkov, N; Dyachenko, Y; Petrova, M; Bondarenko, G; Pustovit, V. (2017). Intelligent and Cognitive Technologies in Education of International Economic Relations Students and Human Resource Development in Enterprises: Methodology in Language. European Journal of Sustainable Development. Publisher: European Center of Sustainable Development, Rome, Italy, Vol 6, No.4, , pp.353-360, DOI: 10.14207/ejsd.2017.v6.n4.p353

Tam, M. (2001). Measuring quality and performance in higher education. Quality in Education, 7(1), 4-54. 